\title{
Science Watchdogs
}

\section{Jaime A. Teixeira da Silva}

\author{
P. O. Box 7, Miki-cho post office, Ikenobe 3011-2, Kagawa-ken, 761-0799, Japan
}

Email:jaimetex@yahoo.com

\section{Doi:10.5901/ajis.2016.v5n3p13}

\begin{abstract}
A new "ethical" elite has arisen in science, the science watchdogs. In response to an inconsistent lack of accountability by scientists, editors and publishers, this new class of individuals, action groups, and anonymous entities has risen in very recent years to the level of "science watchdogs". These individuals are attempting to hold various parties more accountable, or to raise greater public awareness of issues that plague science and science publishing. This letter examines the rapid rise of this new class of science watchdogs and briefly examines what their role, or risk, in science may be. While such efforts are laudable, their efforts and actions are still at an infancy. Thus, it is in fact necessary and important to hold this new class of individuals as accountable as the parties that they are trying to watch over by carefully examining their modus operandii. Most importantly, their personal and professional codes of conduct and possible infringements of ethical or professional boundaries need to be closely scrutinized, so that the repair of ills in science, through constructive criticism, remain fair, and balanced while respecting all parties' freedom of speech. May this letter stimulate greater open and passionate debate about this topic.
\end{abstract}

Keywords: anti-science; awareness; critical; open access; transparency; vigilante

It is now fairly common knowledge that multiple issues are plaguing science, including the lack of accountability, flawed and manipulated peer review, academic fraud and misconduct, gamed indexes and metrics such as the journal impact factor, and a reproducibility crisis, among others. In recent years, there has been an increasing effort, both by individuals and groups, to address these flaws and issues, as a way to regain trust in science and science publishing. This effort is taking place amidst an increase in rules and regulations (primarily for authors) (i.e., the militarization of science; Teixeira da Silva 2016), crack-downs, awareness, whistle-blowing, public shaming and the act of being watched by watchdogs. These watchdogs are referred to as science watchdogs, and some are actively practicing scientists, or journalists. Others yet assume anonymous or pseudonymous identities. Fueled by powerful social media and internet sites and blogs, a message for or against science can now spread like wild fire and cause irreparable damage to a reputation within the space of days or weeks. Never before have scientists or science been challenged by so many critics, and defenders of science's integrity. In some cases, the true personal or professional agenda is unclear, unspecified, or unstated, but clearly have an anti-science agenda (i.e., the purpose is to defame, insult or shame scientists or science-related processes, rather that creating a platform that results in the overall improvement and edification of science through a correction of its faults). In this fairly chaotic and fluid state, one class of individuals, or groups, has begun to rise, both in terms of social profile and in terms of influencing power, the science watchdogs.

Earlier this year (February 4-5, 2016), a small and relatively poorly known - i.e., to scientists - meeting was held in UC California, Davis ((http://icis.ucdavis.edu/?p=826). At that meeting, which involved a surprisingly large number of lawyers, most likely because the meeting was held at the law faculty, and whose key focus was on gaming metrics, 10 individuals or groups were listed, either as watchdogs, or presenting issues related to watchdogs: Jonathan Eisen (UC Davis, Genome Center), Ivan Oransky (Retraction Watch, NYU) (www.retractionwatch.com), John Bohannon (Science Magazine), Elizabeth Wager (Sideview; former COPE Chair 2009-2012), Darren Taichman (Annals of Internal Medicine Vice President), Debora Weber-Wulff (University of Applied Sciences Berlin; VroniPlag Wiki; http://de.vroniplag.wikia.com/wiki/Home), Brandon Stell (The PubPeer Foundation, CNRS) (www.pubpeer.com), and Emmanuel Didier and Catherine Guaspare (EPiDaPo, UCLA). Of note, two other speakers at that meeting were Paul S. Brookes (University of Rochester), of the now shuttered http://www.science-fraud.org/ and Jeffrey Beall, a librarian at the University of Colorado's Auraria Library, and of the blog www.scholarlyoa.com that highlights the issue of "predatory open access journals and publishers". Fiona Godlee (British Medical Journal's editor-in-chief, 2005-2016; http://www.bmj.com/about-bmj/editorial-staff/fiona-godlee), listed alongside Oransky and Beall, were recently collectively described as "three crusaders fighting to clean up bad science" (CBC News 2016). This religious imagery is invoked 
precisely to conjure a hyperbolic perception of a Dark Ages of science in which powerful forces of good and evil - or of opposing theological extremes - are doing battle. More recently, a self-proclaimed science activist, critic and science journalist, Leonid Schneider (https://forbetterscience.wordpress.com/), has also become a prominent and outspoken science watchdog. Then there is a separate class of science watchdog that blogs anonymously, such as Neuroskeptic (http://blogs.discovermagazine.com/neuroskeptic/), or others, who sign their names and comment anonymously on blogs and online discussion boards and social media. Several of these individuals or entities who constitute this new class of science watchdog have taken a prominent center stage on the global front in dealing with issues and problems in science. This is not an exhaustive list of science watchdogs, but does represent some of the currently most vocal.

Unlike government-created watchdogs like the US's Office of Research Integrity, or ORI (https://ori.hhs.gov/), which holds a strict code of conduct, rules of operation and guidelines with which it operates within the law, this new class of watchdogs, sometimes unaffiliated with any organization, or affiliated with self-created "ethical" organizations, operates fairly freely, and in many cases without any academic affiliation, established codes of conduct, or oversight. Indeed, this is their right, but such freedom carries with it the weight of moral responsibility. Over the past few years, some of these individuals have grown rapidly in fame, while others have sought profitable funding through charitable contributions. Using their new found - and relatively unchallenged - popularity, some of these individuals or entities are attempting to push - in some cases very aggressively - their sphere of influence towards policy making and policy control. This may be dangerous not only to scientists, but to society as well, if left unregulated, or unscrutinized. The rise of non-governmental science watchdogs and activists also brings with it a series of risks and concerns. One of the greatest risks lies in the lack of a watchdog that watches over these watchdogs. Blatt (2015) briefly alludes to this in his editorial, in reference to such scrutiny amounting to vigilantism. The outrage that the use of this term sparked among some of these watchdogs, who clearly felt threatened by his editorial, reinforced the notion that freedom of speech, or rather the liberty to criticize scientists, remains fully unregulated, monitored, or challenged. If such individuals or groups are working under their own set of ethical and moral principles, with publicly undeclared conflicts of interest or unclear rules of engagement, this may undermine their rapidly acclaimed credibility. The most glaring example is that of the Paul Brookes web-site that was shut down in 2012 after the insinuation that all cases presented there automatically represented fraud. Yet, thus far, the other watchdogs continue to operate fairly freely, working under the broad umbrella of freedom of speech, often without impunity, even when they err. Most likely few, if any, scientists, editors or publishers would want to challenge science watchdogs for fear of negative feedback, greater public shaming, and thus a negative impact on their personal and professional image. Moreover, few, if any, public web-sites or blogs exist that are holding these watchdogs accountable, or even being critical of them. Unregulated watchdogs, like unregulated science, have the potential for introducing new and even greater risks, uncertainty and instability to science, which is already being rocked by many internal conflicts.

Science watchdogs are important because they introduce a balancing factor in the accountability balance. Their power lies in, to a certain extent, the shame factor, where a negative fact is able to cast even the most prominent or reputable of scientists or individuals under a shady light. Innuendo, hyperbole and poetic license often transform a simple fact into a sensationalist scandal. And this is the bitter-sweet nature of freedom of speech. In the same way that these science watchdogs have risen quickly to power and fame, and are currently enjoying basking in that newfound glory and attention, it is essential to hold them accountable for what they publish, what they state in public and what they create and spread through their blogs, Tweets and Facebook pages, among other social media. It is important to clarify the ethical principles that underlie so-called science journalists and that distinguish them from the ethical principles that scientists are being held to. If there are inequalities, then these need to be exposed, then corrected. Most importantly, a strong and powerful counter-watchdog movement has yet to emerge that holds these science watchdogs accountable. If left in an unregulated state with unprecedented freedoms of expression, there may be even greater risks and dangers to science than science's self-implosive forces.

At the end of the day, recognized problems in science and science publishing need to be openly and frankly addressed. This will involve wide-ranging discussion and no doubt conflicts that need to be resolved. Science watchdogs play an important role in exposing these problems and conflicts, but they and their actions must also be carefully scrutinized and challenged where and when necessary.

\section{Disclaimer and Conflicts of Interest}

The author is both a vigilant scientist and a science vigilante, and could be considered by some to be an independent science watchdog. This can automatically create a potential conflict of interest with any scientist whose work he has scrutinized, or with any editor or publisher he has criticized for not effecting change or correcting the literature 
accordingly. The author declares that he has had several conflicts and shares several differences of opinion, in public and in private, with several of the "science watchdogs" listed in this paper.

\section{References}

Blatt, M.R. (2015) Vigilante science. Plant Physiology 169(2), 907-909. Doi: 10.1104/pp.15.01443

CBC News (2016) Cleaning up bad science. April 19, 2016. http://www.cbc.ca/news/thenational/cleaning-up-bad-science-1.3541786 (last accessed: October 18, 2016)

Teixeira da Silva, J.A. (2016) The militarization of science, and subsequent criminalization of scientists. Journal of Interdisciplinary Medicine 1(2): 214-215. DOI: 10.1515/jim-2016-0031 
